\title{
Análise da eficiência energética, ambiental e econômica entre lâmpadas de LED e convencionais
}

\author{
Analysis of energy efficiency, environmental and \\ economical between LED and conventional lamps
}

\begin{abstract}
Talía Simões dos Santos', Marília Carone Batista², Simone Andréa Pozza', Luciana Savoi Rossi³
\end{abstract}
口-

\begin{abstract}
RESUMO
Os Diodos Emissores de Luz, mais conhecidos como LED's, são componentes eletrônicos semicondutores que conseguem transformar a energia elétrica em luz, diferente das lâmpadas convencionais. O LED é um componente bipolar, que quando passa corrente elétrica, a luz é gerada. As lâmpadas modernas utilizam LED em sua formação, as quais liberam menos calor e utilizam menos energia, sendo assim mais econômicas que as incandescentes e as fluorescentes. Além de apresentarem maior durabilidade que as demais, as lâmpadas LED não promovem o aquecimento dos ambientes internos e seu descarte tem reduzido impacto ambiental. A associação de vantagens ambientais e econômicas torna esta tecnologia atrativa ao consumidor, embora o custo para sua aquisição seja superior aos demais modelos de lâmpadas disponíveis no mercado. Neste estudo foram realizados testes de verificação do fluxo luminoso e eficiência energética, além de análise ambiental das lâmpadas domésticas. Os resultados obtidos comprovaram o potencial da tecnologia LED em relação às demais lâmpadas analisadas, especialmente quanto à questão econômica e ambiental conforme estudos prévios analisados.
\end{abstract}

Palavras-chave: lâmpadas; LED; economia de energia; eficiência energética; sustentabilidade.

\begin{abstract}
Light Emitter Diode, more commonly known as LED's, are semiconductor electronic components that can transform electrical energy into light, unlike conventional lamps. LED has a bipolar component, when polarized, allows the passage of electric current creating light. Modern lamps use LED in their formation, which release less heat, use less energy, and are more economic than incandescent and fluorescent. Besides present more durability than the others, LED lamps do not heat up the environment and their disposals do not attack the environment. The association of environmental and economic advantages makes this technology attractive to consumer, although the cost of acquisition is higher than the other lamps models available in market. The verification of luminous flux and energy efficiency tests were realized in this study, beyond an environmental analysis. The obtained results proved the potential of LED technology due to other analyzed lamps, especially economic and environmental issue as previous studies analyzed.
\end{abstract}

Keywords: lamps; LED; energy savings; energy efficiency; sustainability.

\section{INTRODUÇÃO}

Grande parte da energia elétrica do Brasil é proveniente de usinas hidrelétricas (FRANCISCO, 2009), as quais dependem de um recurso natural finito para geração de energia, tornando assim a redução do consumo energético algo muito importante para a preservação deste recurso. Existem diferentes técnicas para reduzir o consumo de energia, sendo uma, a substituição das lâmpadas ineficientes (lâmpadas incandescentes) por lâmpadas eficientes (Light Emitter Diode - LED) (SAIDUR, 2009). Estudos revelam que o consumo com iluminação artificial é uma parte significante para o consumo total de energia de um país (BLADH \& KRANTZ, 2008).

Iluminação também consome uma quantidade significante das fontes de energia mundial. De acordo com dados estatísticos de 2011, a iluminação consome 7,2\% das fontes de energias primárias desenvolvidas no mundo e são responsáveis por $430 \mathrm{Gkg}$ de emissão de Carbono na atmosfera (POWELL, 2011).

De 2001 a 2010, a média de eficiência do sistema de iluminação instalado aumentou de 45 para $58 \mathrm{~lm}$. $\mathrm{W}^{-1}$. Isto ocorreu devido à $\square$

'Professora Doutora na Faculdade de Tecnologia da Universidade Estadual de Campinas (Unicamp) - Campinas (SP), Brasil. Engenheira Ambiental pelo ISCA Faculdades - Limeira (SP), Brasil.

${ }^{3}$ Professora Doutora no ISCA Faculdades - Limeira (SP), Brasil

Endereço para correspondência: Talía Simões dos Santos - Rua Paschoal Marmo, 1888 - Jd. Nova Itália - 13484-332 - Limeira (SP), Brasil - E-mail: talia@ft.unicamp.br Recebido: 15/10/13 - Aceito: 15/10/15 - Reg. ABES: 125106 
troca de lâmpada incandescente pela lâmpada fluorescente compacta (DOE, 2012a).

Lâmpadas incandescentes são lâmpadas na qual a luz é produzida esquentando o filamento de Tungstênio. A eficiência destas lâmpadas é em torno de 10 a $20 \mathrm{~lm} . \mathrm{W}^{-1}$, dependendo da sua construção e temperatura de operação (DOE, 2012a). A vida útil de uma lâmpada incandescente é em torno de 1.000 horas (OSRAM, 2009; SIMPSON, 2008). Portanto, são consideradas fontes ineficientes de luz, pois $90 \%$ da energia de entrada é perdida como saída quente (BRUNNER et al., 2010), ou seja, são lâmpadas que convertem apenas $5 \%$ da eletricidade consumida em luz, sendo que o restante é eliminado em forma de calor (FERRARI, 2012).

Lâmpadas fluorescentes são aquelas em que a luz é aumentada por uma descarga elétrica contendo um gás ou um vapor interno. Para o propósito de iluminação, uma pequena quantidade de Mercúrio é introduzida no tubo e um material de Fósforo especial é usado para converter a luz ultravioleta em luz visível. Estas lâmpadas têm eficiência e tempo de vida maiores do que as lâmpadas incandescentes. $O$ fator de conversão de uma para outra é de 4 para 1, ou seja, uma lâmpada incandescente de 60 W corresponde a uma lâmpada fluorescente de 15 W (VITO, 2007).

A lâmpada de Light Emitter Diode (Diodo Emissor de Luz - LED) é uma evolução tecnológica que vem ganhando cada vez mais destaque no mercado de lâmpadas. Lâmpadas de LED são dispositivos semicondutores preenchidos com gases e revestidos com diferentes materiais de fósforo.

Antigamente, o LED era utilizado apenas em alguns eletroeletrônicos para indicar se estavam em stand by ou se estavam ligados. Atualmente, são capazes de emitir luz para iluminar um ambiente inteiro, podendo ser utilizados em luminárias domésticas, palcos, semáforos, faróis de automóveis, e até para a iluminação urbana.

A utilização do LED em forma de lâmpada, além de ser um avanço tecnológico, é muito interessante do ponto de vista dos benefícios ambientais, pois seu consumo de energia é consideravelmente inferior às lâmpadas convencionais, como as incandescentes e as fluorescentes compactas. Outros benefícios ambientais das lâmpadas de LED são as características e possibilidades de descarte final de resíduos, além da sua durabilidade. O LED é produzido com materiais atóxicos ao meio ambiente, o que faz com que possa ser descartado sem a necessidade de uma destinação e disposição final especiais. Sua durabilidade é outro aspecto interessante, pois demanda menos trocas o que, consequentemente, gera menos descartes no ambiente. Já a lâmpada fluorescente, por exemplo, contém Mercúrio, o que exige maiores cuidados quanto ao descarte, devido às características nocivas deste elemento.

O LED é prático por ser pequeno e pode ser aplicado em diversos materiais, como plásticos, madeira, e em diversos locais, como vitrines, luminárias, escritórios, residências. A geração de luz não emite calor, e, portanto, não há o aquecimento dos locais onde é instalado, o que amplia a gama de materiais que podem receber a instalação desta lâmpada.

Atualmente, a principal desvantagem do LED é o custo, pois tem o valor mais elevado que as lâmpadas comuns o que dificulta sua comercialização.
Porém, a exemplo de outros países, o LED é bastante utilizado e, com a crescente demanda e procura, a tendência é que seu custo final ao consumidor diminua, tornando assim cada vez mais viável a sua utilização.

Por ser utilizada para produzir iluminação artificial, a lâmpada LED existe não só em cor branca, como as das demais lâmpadas citadas anteriormente (AMAN et al., 2013). De acordo com (DOE, 2011), as lâmpadas LED têm uma eficiência média de $64 \mathrm{~lm}$. W-1 e sua vida útil é de aproximadamente 50.000 horas (AMAN et al., 2013).

Tendo em vista a importância e as vantagens econômicas e ambientais desta tecnologia, este artigo abordará uma comparação entre lâmpada incandescente, lâmpada fluorescente e a lâmpada LED, analisando os consumos de energia, as eficiências energéticas, os preços (custo benefício) e os possíveis impactos ambientais destes equipamentos elétricos.

\section{Aspectos Ambientais}

Os consumidores normalmente adquirem as lâmpadas baseado nas características do seu consumo de potência (em Watts), ao invés de considerar o nível de iluminação (lux). Os principais pontos que são necessários saber são: lumens é uma medida da quantidade de luz ou número total de linhas do fluxo luminoso emitido da fonte de luz; eficiência é uma medida de quantos lumens são emitidos para uma dada potência elétrica de entrada, é medida em lumens por Watt $\left(\operatorname{lm} . \mathrm{W}^{-1}\right)$; e iluminação é uma medida do nível de claridade numa dada área (AMAN et al., 2013).

As lâmpadas incandescentes têm comprovadamente menor eficiência quando comparadas aos demais tipos de lâmpadas existentes. A eficiência média das lâmpadas fluorescentes e das lâmpadas de LED é quase a mesma. Entretanto, estima-se que os tubos de LED tenham maior eficiência se comparados com as lâmpadas de LED.

O uso de Mercúrio em lâmpadas fluorescentes é essencial para que elas funcionem corretamente, mas sua concentração não deve exceder os $5 \mathrm{mg}$ por lâmpada (REY-RAAP \& GALLARDO, 2012). Já as lâmpadas incandescentes e as LED’s não apresentam esta característica, embora certa quantidade de Mercúrio seja utilizada, o que pode representar um risco de contaminação ao ambiente, mesmo que não ocorra a liberação do elemento tóxico enquanto o vidro da lâmpada estiver intacto. Geralmente, o conteúdo de mercúrio varia entre 4 a $5 \mathrm{mg}$, quantidade que não causa danos diretos à saúde humana. Porém, o fato do mercúrio ser cumulativo na cadeia trófica faz com que estes resíduos sejam problemáticos, em especial em situações em que ocorre a acumulação das lâmpadas fluorescentes quebradas. Nestes casos, o elemento liberado pode destruir a camada protetora de ozônio na atmosfera, contaminar corpos hídricos superficiais ou águas subterrâneas e acumular-se nos biomas, na biota, etc. (ENERGY STAR, 2010; USEPA, 2012).

O mercúrio pode afetar todos os grupos de organismos e Ecossistemas, incluindo microrganismos da água e solo e a fauna de uma maneira geral (WANG et al., 2012). A presença desta substância no ambiente é um risco eminente à saúde humana, há relatos na literatura sobre casos de Alzheimer, Parkinson e mortalidade infantil relacionados à exposição à contaminação 
ambiental por mercúrio (WANG et al., 2012; BOSE-O'REILLY et al., 2010). Atualmente, apenas $20 \%$ das lâmpadas fluorescentes podem ser recicladas, processo que é considerado muito oneroso (AMAN et al., 2013).

Outra questão ambiental a ser ressaltada está relacionada diretamente com o consumo e aproveitamento da energia a partir da lâmpada de LED. De acordo com DOE (2012b), a lâmpada incandescente tem maior impacto ambiental comparado com as lâmpadas fluorescente e LED devido à baixa eficiência e a alta quantidade de energia requerida para produzir luz, o que aumenta as chances de desperdício de matéria no ambiente na forma de energia.

\section{Lâmpada de LED}

Por definição, o diodo LED é um componente eletrônico semicondutor, com a mesma tecnologia utilizada nos chips de computadores, que tem a propriedade de transformar energia elétrica em luz. Ele não utiliza filamentos metálicos, radiação ultravioleta, nem descarga de gases. É um componente bipolar, tem um terminal chamado cátodo e outro chamado ânodo, que, quando polarizado, permitem a passagem de corrente elétrica, gerando luz (LABORATÓRIO DE ILUMINAÇÃO, 2012). A lâmpada LED é fabricada com este material semicondutor, que, quando é percorrido por corrente elétrica, emite luz. Materiais semicondutores possuem uma resistência situada entre materiais condutores e isolantes. Os principais materiais semicondutores empregados na eletrônica são o germânio e o silício, sendo este último o mais utilizado (STRYHALSKI, 2012). Destaca-se, ainda, que os materiais semicondutores não são prejudiciais ao meio ambiente.

O LED não é uma invenção recente, foi desenvolvido em fase experimental em 1963, tinha baixa luminosidade e cor vermelha. Em 1975, descobriu-se o de cor verde e em 1995 descobriu-se o LED de cor branca. Hoje em dia, a tecnologia de LED sofreu várias mudanças e evoluções, porém, essas descobertas iniciais foram fundamentais para chegar ao resultado atual.

No início dos anos 1990, houve a principal revolução do LED e a possibilidade de aplicá-lo no setor automotivo, por exemplo. Após obter-se LED's com comprimento de ondas menores, nas cores azul, verde e ciano, tecnologia esta que propiciou a obtenção do LED branco, e consequentemente, todos os espectros de cores (LPR LEDs, 2011).

Com o avanço da tecnologia LED, foi criada a lâmpada de LED, uma lâmpada de qualidade e longa duração; tecnologia esta que viria para inovar o mercado de lâmpadas.

A lâmpada de LED utiliza $82 \%$ menos energia elétrica que uma lâmpada incandescente, garantindo uma economia significativa na conta de energia. Uma lâmpada doméstica de LED tem durabilidade de 50.000 horas, contra 1.000 horas de uma incandescente e 6.000 horas de uma florescente, o que permite diminuir a quantidade de trocas de lâmpadas ou gastos com manutenções. Podem ser fabricadas em diversos tamanhos e formatos milimétricos, podendo ser usadas em vários ambientes e para inúmeras utilidades. Uma característica interessante é o fato de que sua luz não desbota ou danifica tecido, fato que tem contribuído para que lojas de vestuário optem por trocar suas iluminações convencionais em vitrine pela tecnologia de iluminação por LED.

Mais recentemente, o mercado consumidor tem aumentado progressivamente o consumo pelas lâmpadas de LED. Há indícios de que, a cada dois anos, o custo de fabricação caia pela metade e o poder de iluminação dos LED's dobre, o que tem possibilitado a queda dos preços das lâmpadas de LED ao consumidor. Além disso, fato importante que merece ser ressaltado é que as lâmpadas LED exigem menos manutenção que as lâmpadas convencionais (DALMAZO, 2009). Mesmo com estas tendências à mudança, a maior desvantagem da tecnologia de LED ainda é seu preço final. Estudos indicam que o preço de uma lâmpada LED doméstica pode chegar a trinta e sete vezes mais que uma lâmpada incandescente, e nove vezes mais que uma lâmpada fluorescente compacta. Porém, grandes empreendimentos como hotéis, grandes redes varejistas e indústrias já estão aderindo à nova tecnologia (DALMAZO, 2009).

\section{Comparação de Consumo Energético da LED com Lâmpadas Convencionais}

Uma lâmpada incandescente comumente utilizada em residências é a lâmpada de 60 Watts. Em uma casa com 10 lâmpadas ligadas em uma média de 6 horas diárias, por um período de cinco anos, estas lâmpadas gastarão mais de $6.000 \mathrm{kWh}$, o que significa um grande consumo de energia elétrica (ENERGIA LIMPA, 2009).

As lâmpadas fluorescentes compactas de 15 ou $18 \mathrm{~W}$ substituem uma lâmpada incandescente de $60 \mathrm{~W}$, porém com consumo em torno de $1.900 \mathrm{kWh}$, considerando os mesmos padrões, bastante econômico quando comparada a incandescente (ENERGIA LIMPA, 2009).

Lâmpadas de LED equivalentes a $60 \mathrm{~W}$ da incandescente e a $15 \mathrm{~W}$ da fluorescente necessitam apenas de 8 Watts para emitir luz, refletindo num gasto bem menor que as demais, cerca de $1.000 \mathrm{kWh}$ (ENERGIA LIMPA, 2009).

\section{Descarte final de resíduos}

A NBR 10.004 (ABNT, 2004) define resíduos como: "Resíduos nos estados sólido e semi-sólido, que resultam de atividades de origem industrial, doméstica, hospitalar, comercial, agrícola, de serviços e de varrição. Ficam incluídos nesta definição os lodos provenientes de sistemas de tratamento de água, aqueles gerados em equipamentos e instalações de controle de poluição, bem como determinados líquidos cujas particularidades tornem inviável o seu lançamento na rede pública de esgotos ou corpos de água, ou exijam para isso soluções técnica e economicamente inviáveis em face à melhor tecnologia disponível". Para todos esses resíduos sólidos deve ser feita uma classificação onde se separa resíduos perigosos os quais necessitam de descartes específicos, dos resíduos não perigosos, que podem ser depositados em aterros sanitários convencionais.

As lâmpadas fluorescentes são compostas por componentes químicos altamente poluentes e tóxicos ao meio ambiente e, portanto, essas lâmpadas não podem ser descartadas em aterros públicos diretamente, 
necessitando de uma prévia recuperação destes compostos para evitar os danos ambientais.

Anualmente, só no Brasil, são descarregados na natureza perto de 3,5 toneladas de mercúrio contidas nas 85 milhões de lâmpadas descartadas nos aterros públicos, que vêm, sistematicamente, contaminando o ar em nosso meio ambiente (CETRIC, 2012).

O Brasil é o quarto país que mais consome lâmpada fluorescente no mundo. $\mathrm{O}$ descarte é realizado por empresas que recebem estas lâmpadas e encaminham para reciclagem em empresas específicas (SEBBEN, 2012). A Política Nacional de Resíduos Sólidos (BRASIL, 2010) estabeleceu a obrigatoriedade de implantação de sistemas de logística reversa para lâmpadas fluorescentes, responsabilizando os fabricantes e distribuidores pelo descarte final (SILVA, 2013). Na prática, ninguém quer arcar com os custos deste descarte. $\mathrm{O}$ valor da reciclagem é quase $30 \mathrm{a}$ $40 \%$ o custo de uma lâmpada nova (SEBBEN, 2012).

O estudo de Laruccia et al. (2011) abordou a decisão do consumidor sobre a eliminação de lâmpadas fluorescentes usadas, em São Paulo. Os autores verificaram que, a maioria das pessoas descartava lâmpadas fluorescentes no lixo orgânico, mas admitiam que o local adequado para isto fosse a reciclagem ou coleta seletiva. Também afirmam que o maior obstáculo para descarte de lâmpadas é a ignorância da população sobre a disposição de lâmpadas, julgando não ter encontrado alternativas para descarte adequado no Brasil.

As lâmpadas incandescentes convencionais são produzidas a partir de vidro e metal e, portanto, não contêm materiais prejudiciais ao meio ambiente. Na verdade, não há problema em se descartar lâmpadas incandescentes em aterros sanitários, porém, elas não devem ser jogadas em lixos para reciclagem de vidros, pois o tipo de vidro usado na produção de lâmpadas é diferente dos vidros convencionais. Um problema é que a vida útil das lâmpadas incandescentes é menor se comparada com as lâmpadas de LED ou fluorescentes, o que gera uma quantidade grande de resíduos a serem descartados nos aterros.

No caso das lâmpadas LED, $98 \%$ dos materiais em sua composição são recicláveis e não contêm metais pesados, como o mercúrio, em sua produção, sendo menos agressivas ao homem. Além disso, quando são desligadas, o seu tempo de reacendimento é menor (ECYCLE, 2012).

\section{METODOLOGIA}

Nesta seção, estão apresentados os ensaios realizados para avaliar o consumo das lâmpadas de LED, lâmpada incandescente e lâmpada fluorescente durante um período de 24 horas.

O estudo foi dividido em duas fases, sendo ambas realizadas no Laboratório de Eletrônica do Instituto Superior de Ciências Aplicadas (ISCA Faculdades), durante o ano de 2012. Na primeira fase, os testes foram iniciados no dia 11 de junho e finalizados em 14 de junho de 2012. A segunda fase ocorreu no dia 17 de agosto de 2012.
Os materiais necessários para a realização dos ensaios foram:

- Lâmpada incandescente de $60 \mathrm{~W}$ da marca OSRAM de $127 \mathrm{~V}$;

- Lâmpada Fluorescente de 15 W da marca FLC de 127 V;

- Lâmpada LED de 4,5 W da marca LClight de 127 V;

- Medidor de consumo da marca Intertek.

A escolha das lâmpadas a serem testadas foi realizada com base em sua equivalência de potência, o que permitiu comparações em um mesmo nível. Abaixo seguem as fotos das lâmpadas utilizadas no experimento (Figura 1).

As lâmpadas foram ligadas a rede elétrica para medição do consumo energético de cada uma utilizando-se um medidor de consumo Intertek, o qual é capaz de medir: consumo em kWh, voltagem e amperagem.

Estabeleceu-se que, durante o período em que se realizaram as medições, as lâmpadas permaneceram ligadas por um período de 24 horas seguidas, sem interrupções. Neste período os dados de medição foram coletados. O primeiro ensaio foi realizado com a lâmpada de LED de $4,5 \mathrm{~W}$, iniciando no dia 11 de junho de 2012, às 18 horas. Na Figura 2 é mostrada a lâmpada LED em teste.

O segundo ensaio no dia 12 de junho de 2012, às 18 horas e 40 minutos, foi com a medição de consumo com a lâmpada fluorescente de 15 W, como na Figura 3.

O terceiro e último ensaio, com a lâmpada incandescente de $60 \mathrm{~W}$, que teve inicio em 13 de junho de 2012, às 18 horas e 50 minutos, finalizando após 24 horas em 14 de junho de 2012, às 18 horas e 50 minutos. Os dados obtidos foram analisados e submetidos à análise dos resultados. Na Figura 4 é apresentada a lâmpada incandescente em teste.

Na segunda fase dos estudos, a eficiência das lâmpadas foi verificada por meio do fluxo luminoso. Os materiais necessários para a realização desses ensaios foram:

- As mesmas lâmpadas utilizadas anteriormente;

- Luxímetro Digital (Digital Lux Meter) da marca MINIPA;

- Caixa de madeira de $1 \mathrm{~m}^{3}$.

A caixa de madeira foi utilizada para padronizar a área de dimensionamento da iluminância, fazendo com que a quantidade de lux seja a mesma

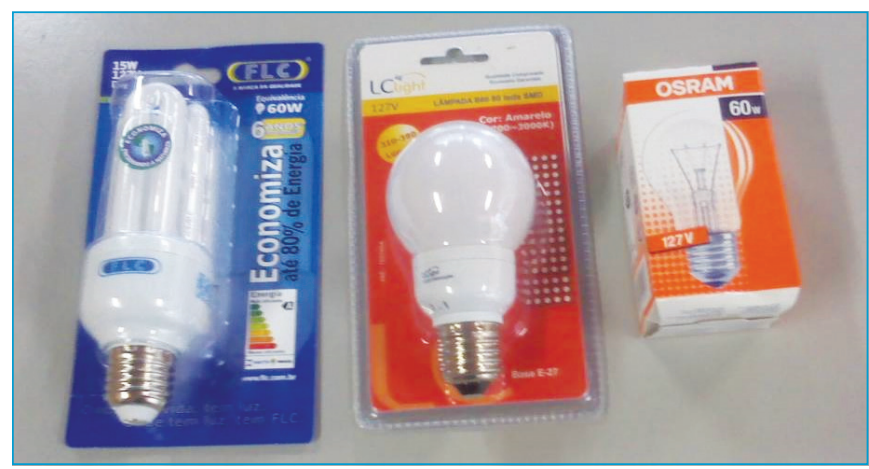

Figura 1 - Lâmpadas utilizadas no experimento. 
de lumens, uma vez que a área da caixa é de $1 \mathrm{~m}^{2}$ e a iluminância (lux) é a relação entre fluxo luminoso (lm) e a área. O aparelho utilizado para medir a iluminância de cada lâmpada foi o luxímetro. Portanto, com este aparelho, foi possível medir o fluxo luminoso, ou seja, a radiação total da fonte luminosa, que é a quantidade de luz emitida por uma fonte (FERREIRA, 2010).

Na primeira etapa da segunda fase do trabalho, foi testada a lâmpada incandescente e a mesma foi ligada à energia e fixada na tampa superior da caixa de madeira. O luxímetro foi posicionado sob a lâmpada a fim de medir o fluxo luminoso da mesma (Figura 5).

Posteriormente, o luxímetro foi posicionado abaixo da lâmpada fluorescente, da mesma forma que o teste anterior, conforme a Figura 6.

Por fim o teste também foi realizado com a lâmpada de LED, conforme Figura 7.

O dimensionamento do fluxo luminoso é rápido, e em instantes o resultado já aparece no visor o luxímetro.

\section{RESULTADOS E DISCUSSÃO}

A Tabela 1 apresenta um comparativo entre as três lâmpadas utilizadas nos ensaios da primeira fase.

Após o período de análise, a lâmpada LED consumiu apenas $0,095 \mathrm{kWh}$.

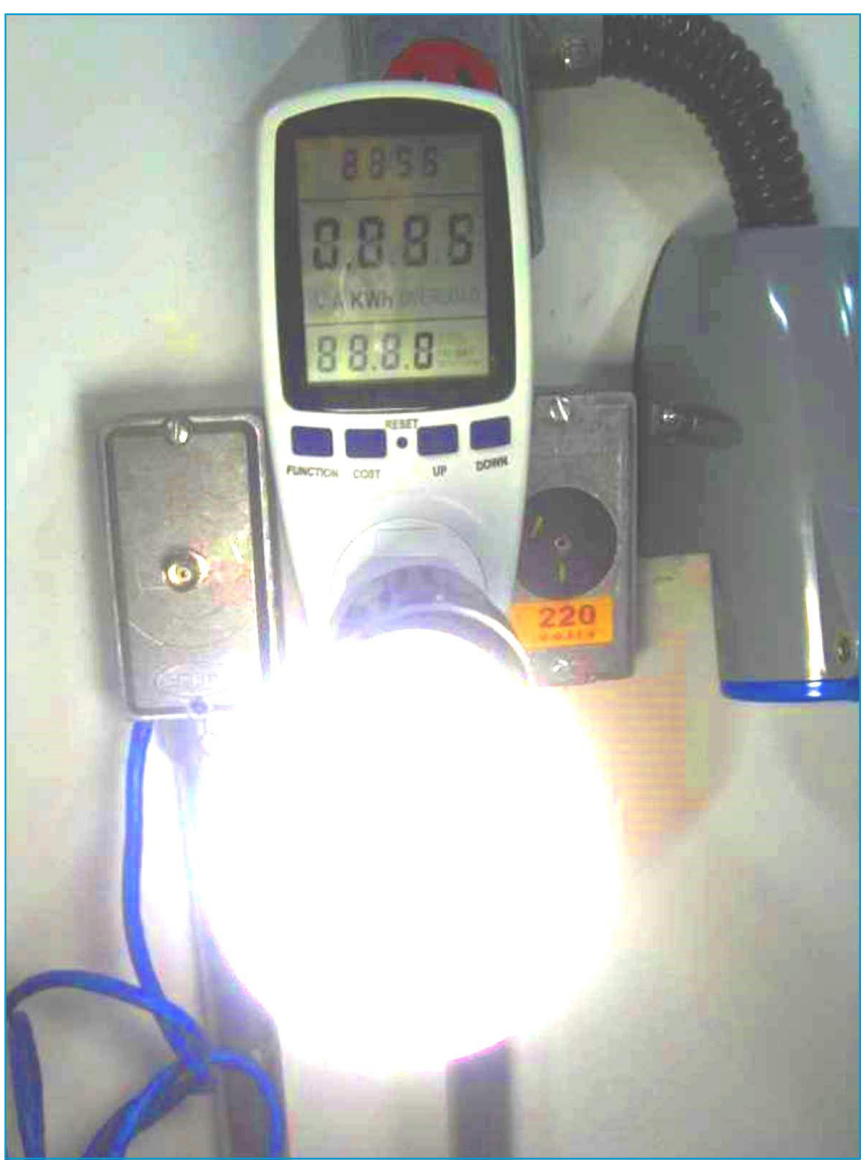

Figura 2 - Lâmpada LED em teste.
A medição da lâmpada fluorescente foi finalizada às 18 horas e 40 minutos do dia 13 de junho de 2012. O medidor apresentou o consumo de $0,335 \mathrm{kWh}$. Já com a lâmpada incandescente, o medidor de consumo marcou 1,428 kWh.

Ao final do período de avaliação, observou-se que a lâmpada de LED confirmou seu padrão de consumo, ou seja, foi mais econômica quando comparada com as lâmpadas incandescente e fluorescente. Observou-se que ela foi capaz de usar apenas 6,65\% de kWh em relação à uma lâmpada incandescente, ou seja, uma economia de 93,35\%, sendo que na seção 1.2 observou-se que a lâmpada LED utilizou $82 \%$ menos energia elétrica que uma lâmpada incandescente. Além disso, usou apenas $28,36 \%$ em relação à uma lâmpada fluorescente, resultando uma economia de $71,64 \%$ durante o período avaliado.

Outro ponto bastante importante, além da economia de energia já verificada, é o valor investido. Conforme analisado, estudos indicam que um preço da lâmpada LED pode chegar a 37 vezes mais que uma incandescente e 9 vezes mais que a fluorescente. Neste trabalho isso foi confirmado, sendo que o preço da LED foi de 37,66 vezes a mais que a incandescente e 8,34 a mais que a fluorescente (Tabela 1).

Em relação aos ensaios da segunda fase, no teste com a lâmpada incandescente, o fluxo luminoso foi de $338 \mathrm{~lm}$. Já no teste com a lâmpada fluorescente, foi de $316 \mathrm{~lm}$. No último teste com a lâmpada de LED, foi de $160 \mathrm{~lm}$.

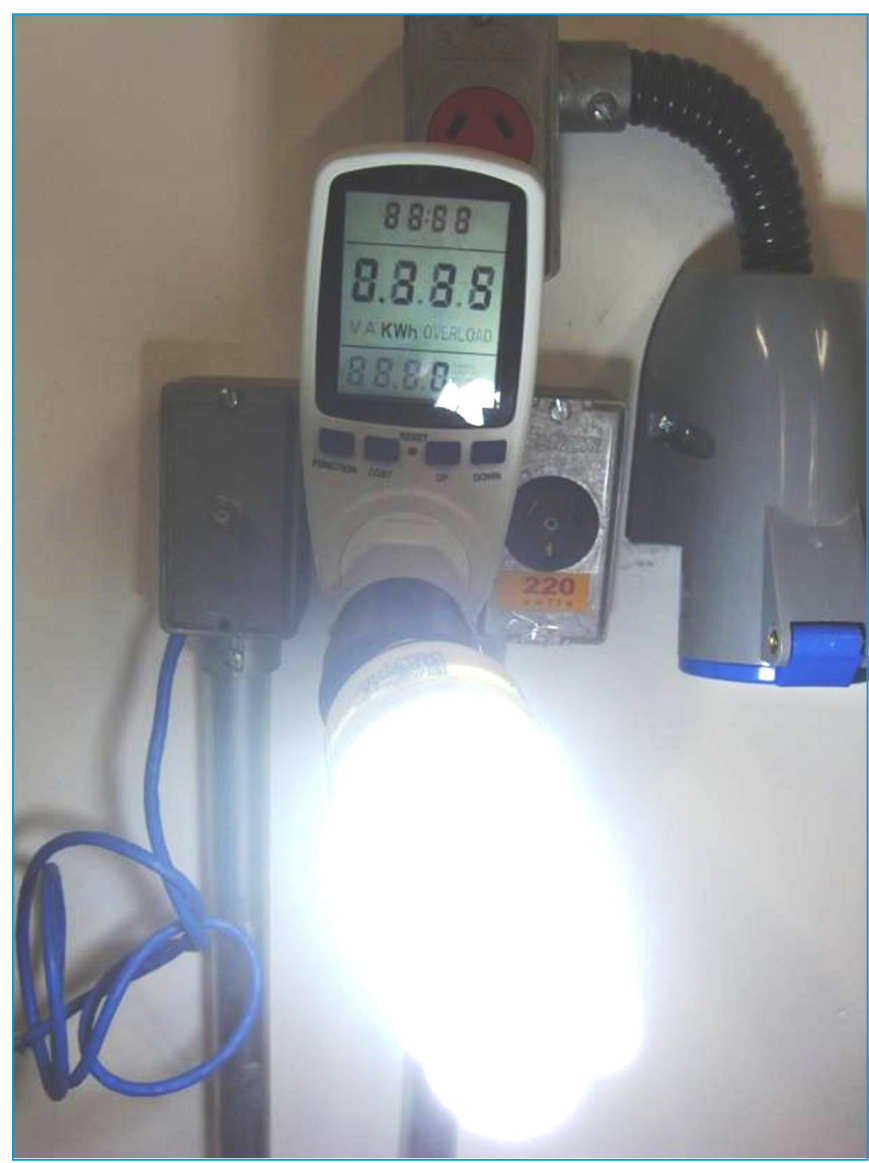

Figura 3 - Lâmpada fluorescente em teste. 
A Tabela 2 mostra os resultados dos fluxos luminosos de cada uma das lâmpadas testadas e sua eficiência.

Ao final dos testes de fluxo luminoso, percebe-se que a lâmpada incandescente tem fluxo luminoso maior que as demais lâmpadas. A lâmpada fluorescente tem apenas $22 \mathrm{~lm}$ a menos que a incandescente. E a lâmpada de LED tem quase que metade do fluxo luminoso das demais, apenas $160 \mathrm{~lm}$, porém, sua eficiência é maior.

De acordo com o INMETRO (2013), a lâmpada incandescente de $60 \mathrm{~W}$ deve ter uma eficiência energética média de $14,4 \mathrm{~lm}$. W ${ }^{-1}$. Porém, o teste feito neste trabalho apresentou uma eficiência de apenas 5,63 lm. $\mathrm{W}^{-1}$. Para efeito de comparação e valorização das análises, utilizou-se os resultados obtidos em Torres et al. (2009), cuja eficiência luminosa foi de 1,72 lux.W' ${ }^{-1}$, e a iluminância foi de 103 lux. Com relação às lâmpadas fluorescentes, eles obtiveram uma iluminância de 161 lux e eficiência de 9,47 lux. $\mathrm{W}^{-1}$. Portanto, obteve-se resultado mais próximo ao recomendado pelo Inmetro, pois a eficiência obtida foi de 21,07 lm.W-1 (Tabela 3).

Vale ressaltar que, em Torres et al. (2009), também foi utilizada uma lâmpada incandescente de $60 \mathrm{~W}$ e uma fluorescente compacta de $15 \mathrm{~W}$. Além disso, como a iluminância também foi medida a 1 metro de distância, pode-se dizer que é similar ao fluxo luminoso e a eficiência luminosa é equivalente à eficiência energética (vide Tabela 2). Eficiência energética é a relação entre a quantidade de energia que se utiliza em uma

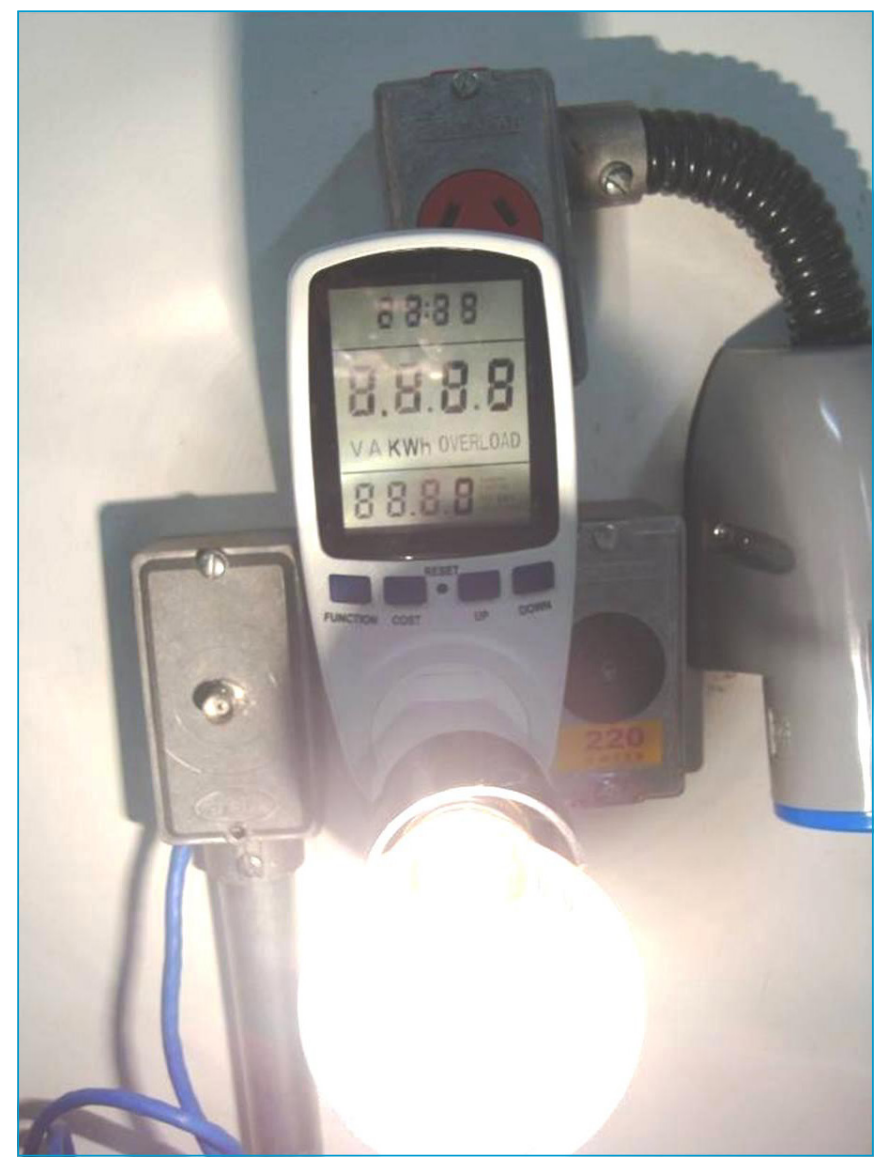

Figura 4 - Lâmpada incandescente em teste.

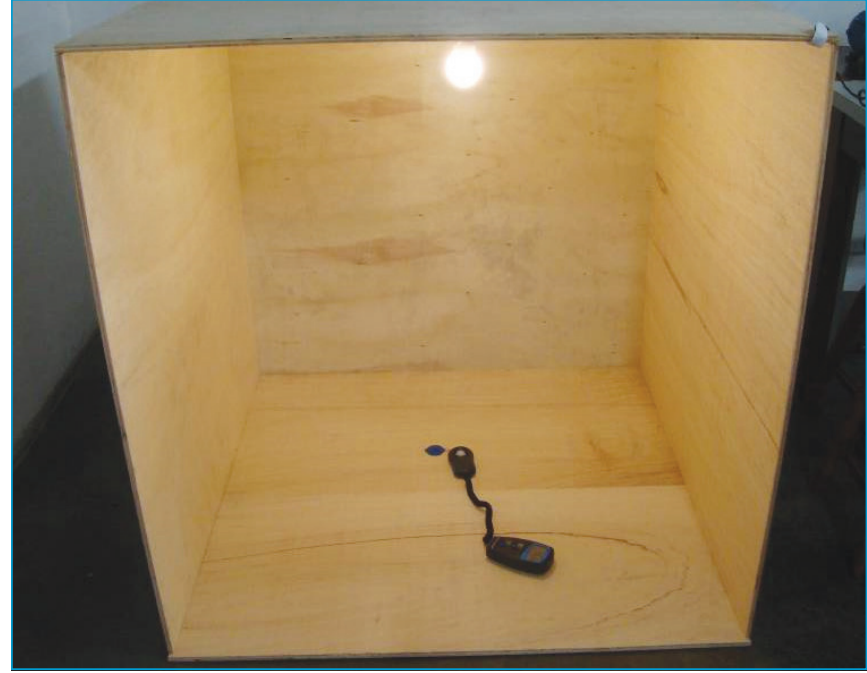

Figura 5 - Teste de luminosidade com a lâmpada incandescente.

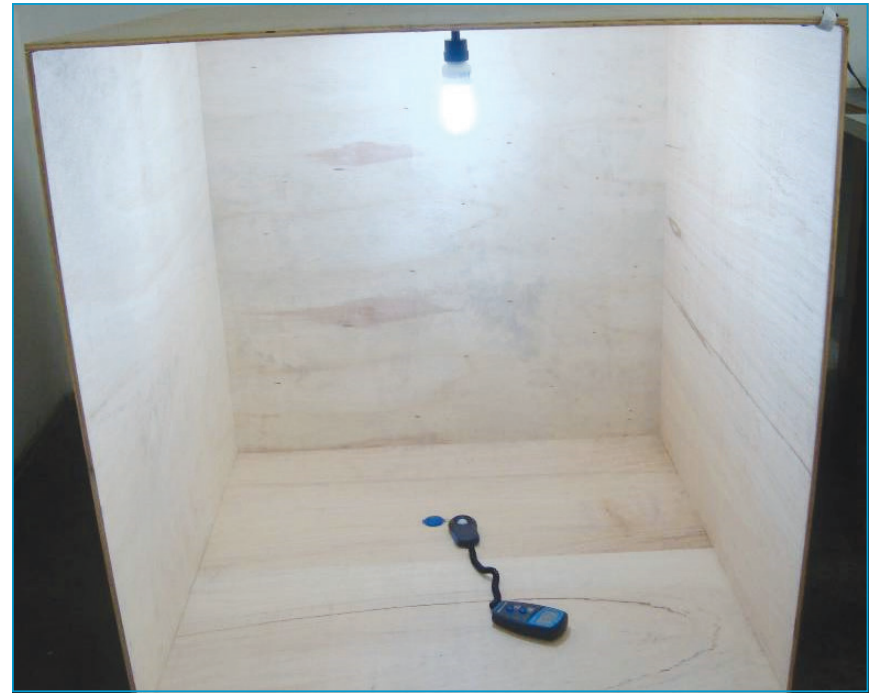

Figura 6 - Teste de luminosidade com a lâmpada fluorescente.

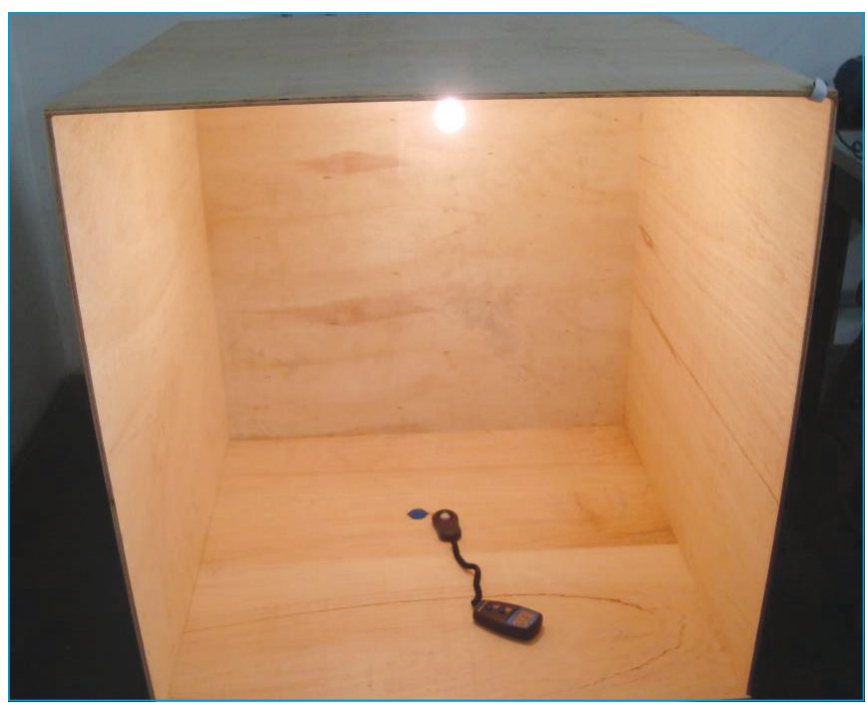

Figura 7 - Teste de luminosidade com a lâmpada LED. 
Tabela 1 - Comparativo de custo/benefício entre as lâmpadas estudadas.

\begin{tabular}{l|c|c|c|c|c}
\hline Lâmpada & Potência (W) & Preço (R\$) & Gastos em KWh (24 horas) & Gasto em 30 dias (R\$ 0,366040 KWh) & Retorno Investimento \\
\hline Incandescente & 60 & 1,75 & 1,428 & 15,68 & - \\
\hline Fluorescente & 15 & 7,90 & 0,335 & 3,67 & 1 mês \\
\hline LED & 4,5 & 65,90 & 0,095 & 1,04 & 5 meses \\
\hline
\end{tabular}

Tabela 2 - Fluxo luminoso das lâmpadas incandescente, fluorescente e de LED.

\begin{tabular}{l|c|c}
\hline Lâmpada & Fluxo luminoso (Im) & $\begin{array}{c}\text { Eficiência energética } \\
(\text { Im.W'1) }\end{array}$ \\
\hline Incandescente (60 W) & 338 & 5,6333 \\
\hline Fluorescente (15 W) & 316 & 21,0667 \\
\hline LED $(4,5$ W) & 160 & 35,5556 \\
\hline
\end{tabular}

Tabela 3 - Resultados de Torres et al. (2009) para efeito de comparação com a Tabela 2.

\begin{tabular}{l|c|c} 
Lâmpada & Iluminância a 1 m (lux) & $\begin{array}{c}\text { Eficiência luminosa } \\
\text { (lux.W-1) }\end{array}$ \\
\hline Incandescente (60 W) & 103 & 1,72 \\
\hline Fluorescente (15W) & 161 & 9,47 \\
\hline
\end{tabular}

atividade e a que está disponível para sua realização, ou seja, requer o menor gasto de energia possível para desenvolver um serviço.

Para finalizar, pode-se perceber que a lâmpada de LED obteve a maior eficiência energética $\left(35,55 \mathrm{~lm} . \mathrm{W}^{-1}\right)$. De acordo com DOE (2011), as lâmpadas LED têm em média $64 \mathrm{~lm} . \mathrm{W}^{-1}$.

É importante enfatizar que os ensaios realizados neste artigo foram feitos em um ambiente normal, ou seja, com interferência das harmônicas na qualidade de energia. Mesmo assim, pôde-se perceber que os resultados foram satisfatórios.

\section{CONCLUSÕES}

Eficiência energética é um tema bastante abordado atualmente no Brasil, devido aos problemas hídricos e, consequentemente, elétricos. Por isso, optou-se por fazer a análise proposta neste trabalho para enfatizar a importância da utilização racional de energia.

A partir da pesquisa realizada, pode-se constatar que a lâmpada de LED mostrou-se mais econômica quando comparada com as lâmpadas comumente usadas nas residências e indústrias do Brasil. É uma lâmpada relativamente cara no mercado atual, porém, como seu consumo de energia é muito menor que as demais, o retorno de investimento na troca das lâmpadas é rápido.

No presente trabalho, foi possível avaliar os benefícios da lâmpada de LED para o consumidor e o meio ambiente, uma vez que a lâmpada tem uma vida útil longa, o que garante menor troca de lâmpadas no decorrer dos anos, além da economia na conta de energia do consumidor. Para o meio ambiente, é uma alternativa de mitigar a poluição, pois a composição da lâmpada de LED não é nociva a ele tem maior durabilidade, minimiza a quantidade de lâmpadas a serem descartadas. Já a lâmpada incandescente tem durabilidade inferior, aumentando o número de trocas e descartes, e o vidro é composto por pequenas partículas de metal, devendo ser tratado separadamente dos vidros recicláveis. A lâmpada fluorescente é composta por Mercúrio e sua descontaminação é um processo caro e demorado. Essa descontaminação se faz necessária, pois o mercúrio descartado de forma incorreta compromete a qualidade do solo e dos corpos d'água.

Quanto ao teste de fluxo luminoso, a lâmpada de LED foi bem inferior comparado com as outras lâmpadas, e isso pode ter ocorrido por diversos fatores, como por exemplo, o fato de ser feita com material leitoso. Porém, o mais importante é o resultado da eficiência destas lâmpadas e, como pode ser visto na Tabela 2, a lâmpada de LED foi a que obteve maior eficiência energética. Mas o principal motivo é o fato de ter sido realizado em um ambiente normal de trabalho (laboratório de eletrônica) e não nas condições ideais como são feitos os testes padrões.

A lâmpada de LED é uma tecnologia nova, que vem se aprimorando cada vez mais, o que faz acreditar que sua eficiência vem aumentando com o decorrer de novas descobertas, e o preço de seus componentes barateando ao ponto de ser mais acessível à população. Tendo em vista a proibição das lâmpadas incandescentes com potência inferior a $100 \mathrm{~W}$ e o preço da lâmpada de LED já estar mais acessível, a compatível com a deste trabalho custa hoje aproximadamente $\mathrm{R} \$ 52,90$, a tendência é que os consumidores troquem de lâmpadas.

\section{REFERÊNCIAS}

ASSOCIAÇÃO BRASILEIRA DE NORMAS TÉCNICAS - ABNT. (2004) NBR 10004: Resíduos Sólidos-Classificação. Rio de Janeiro. ANBT. 71p.

AMAN, M.M.; JASMON, G.B.; MOKHLIS, H.; BAKAR, A.H.A. (2013) Analysis of the performance of domestic lighting lamps. Energy Policy, v. 52, p. 482-500.
BLADH, M. \& KRANTZ, H. (2008) Towards a bright future? Household use of electric light: a microlevel study. Energy Policy, v. 36, p. 3521-3530.

BOSE-O'REILLY, S.; MCCARTY, K.M.; STECKLINH, N.; LETTMEIER, B. (2010) Mercury exposure and children's health. Current Problems in Pediatric and Adolescent Health Care, v. 40. p. 186-215. 
BRASIL. (2010) Lei no 12.305/10 - Política Nacional de Resíduos Sólidos (PNRS). Disponível em: <http://www.planalto.gov.br/ccivil_O3/_ ato2007-2010/2010/lei/12305.htm> Acesso em: 29 jan. 2015.

BRUNNER, E.J.; FORD, P.S.; MCNULTY, M.A.; THAYER, M.A. (2O10) Compact fluorescent lighting and residential natural gas consumption: testing for interactive effects. Energy Policy, v. 38, p. 1288-1296.

CETRIC. (2012) Central de tratamento e disposição de resíduos industriais e comerciais. Disponivel em: <http://www.cetric.com.br/ index.php?PG=opl>. Acesso em: 7 jun. 2012

DALMAZO, L. (2009) Sua lâmpada será assim. Revista Exame. Edição 0935. Disponível em: <http://exame.abril.com.br/revista-exame/edicoes/0935/ noticias/sua-lampada-sera-assim-416500>. Acesso em: 16 maio 2012.

ECYCLE. (2012) Lâmpadas LED podem ser recicladas? Disponível em: <http://www.ecycle.com.br/component/content/ article/49-lampadas/685-lampadas-led-podem-ser-recicladas.html>. Acesso em: 7 jun. 2012.

ENERGIA LIMPA. (2009) A reinvenção da luz. Revista Veja. Edição 2145 - ano 42 - n 52. 30 de dezembro de 2009. Disponível em: <http:// veja.abril.com.br/acervodigital/home.aspx>. Acesso em: 28 maio 2012.

ENERGY STAR. (2010) Information on Compact Fluorescent Light Bulbs (CFLS) and Mercury. Energy Star Program: U.S. Department of Energy. Disponível em: <http://www.energystar.gov/ia/partners/ promotions/change_light/downloads/Fact_Sheet_Mercury.pdf> Acesso em: 01 ago. 2012

FERRARI, B. (2012) Uma luz no debate ambiental: a era das lâmpadas incandescentes está chegando ao fim, e as novas tecnologias que estão despontando prometem reduzir a conta de luz e o impacto no meio ambiente. Revista Exame, v. 46, n. 21, p. 120.

FERREIRA, R.A.F. (2010) Manual de Luminotécnica. Disponível em: <http://www.ufjf.br/ramoieee/files/2010/08/Manual-Luminotecnica. pdf>. Acesso em: 20 out. 2012.

FRANCISCO, W.C. (2009). Energia Hidrelétrica. Disponível em: <http:// www.mundoeducacao.com.br/geografia/energia-hidreletrica.htm>. Acesso em: 16 maio 2012

INMETRO. (2013) Tabelas de Eficiência Energética. Disponível em: <http:// www.inmetro.gov.br/consumidor/tabelas.asp>. Acesso em: 3 ago. 2012.

LABORATÓRIO DE ILUMINAÇÃO. (2O12) LED - o que é, e como funciona. Disponível em: <http://www.iar.unicamp.br/lab/luz/dicasemail/ led/dica36.htm>. Acesso em: 16 maio 2012.

LARUCCIA, M.M.; NASCIMENTO, J.V.; DEGHI, G.J.; GARCIA, M.G. (2O11) A Study of consumer behavior on recycling of fluorescent lamps in São Paulo, Brazil. International Journal of Business Administration, v. 2. n. 3, p. 101-112.

LPR LEDs. (2011) O que é LED. Disponível em: <http:// mais.uol.com.br/view/15xyaw05u8kp/o-que-e-led--lpr-leds04028C9B346CCCA92326?types=A\&>. Acesso em: 28 maio 2012

OSRAM. (2009) Life cycle assessment of illuminants: a comparison of light bulbs, compact fluorescent lamps and LED lamps. Germany. p. 26.
POWELL, K. (2011) Panel 4: lessons from the field. Solid-State Lighting Program: U.S. Department of Energy. Disponivel em: <http://energy.gov/ eere/ssl/solid-state-lighting>. Acesso em: 3 ago. 2012.

REY-RAAP, N. \& GALLARDO, A. (2012) Determination of mercury distribution inside spent compact fluorescent lamps by atomic absortion spectrometry. Waste Management, v. 32, p. 944-948.

SAIDUR, R. (2009) Energy consumption, energy savings, and emission analysis in Malaysian Office buildings. Energy Policy, v. 37, p. 4104-4113.

SEBBEN, E. (2012) Alto custo dificulta o descarte de lâmpadas. Disponível em: <http://www.ecodesenvolvimento.org/posts/2012/ outubro/alto-custo-dificulta-o-descarte-de-lampadas-afirma?tag=rr> Acesso em: 29 jan. 2015

SILVA, F.R. (2013) Impactos Ambientais Associados à Logística Reversa de Lâmpadas Fluorescentes. InterfacEHS - Revista de Saúde, Meio Ambiente e Sustentabilidade, v. 8, n. 1, p. 42-69.

SIMPSON, R.S. (2008) Lighting Control: Technology and Applications. Focal Press. p. 575.

STRYHALSKI, J. (2012) Semicondutores, Um pouco de Física do Estado Sólido. Udesc Joinville. Disponível em: <http://www.mundofisico. joinville.udesc.br/index.php?idSecao=110\&idSubSecao=\&idTexto=49> Acesso em: 07 jun. 2012

TORRES, I.S.M.; SOUSA, F.P.F.; FERREIRA, T.V.; LUCIANO, B.A. (2009) Lâmpadas Fluorescentes e Distorções Harmônicas: Eficiência Energética e Qualidade de Energia Elétrica. Anais do VIII CBQEE Conferência Brasileira sobre Qualidade de Energia Elétrica, Blumenau.

UNITED STATES OF AMERICA DEPARTMENT OF ENERGY - DOE. (2O11) Lighting energy efficiency \& renewable energy. US Department of Energy. Disponível em: <http://www.eere.energy.gov/basics/buildings/ lighting.html>. Acesso em: 25 jul. 2012.

UNITED STATES OF AMERICA DEPARTMENT OF ENERGY - DOE. (2O12a) U. S. lighting market characterization. Solid-State Lighting Program: U.S. Department of Energy. Disponivel em: <http://apps1.eere.energy.gov/buildings/ publications/pdfs/ss/2010-Imc-final-jan-2012.pdfs. Acesso em: 1 ago. 2012.

UNITED STATES OF AMERICA DEPARTMENT OF ENERGY - DOE. (2012b) Life-cycle assessment of energy and environmental impacts of LED lighting products (Part 2: LED Manufacturing and Performance). Solid-State Lighting Program: U.S. Department of Energy. Disponível em: <http://apps1.eere.energy.gov/buildings/publications/pdfs/ssl/2012 led_lca-pt2.pdf>. Acesso em: 1 ago. 2012.

UNITED STATES ENVIRONMENTAL PROTECTION AGENCY - USEPA. (2012) Compact Fluorescent Light Bulbs (CFLs). Disponível em: <http:// www.epa.gov/cfl/cfl-hg.html> Acesso em: 01 ago. 2012.

VITO. (2007) Eco-design study Lot 19-Domestic Lighting. Preparatory Studies for Eco-design Requirements of EuPs. Disponível em: <http:/l www.eup4light.net/assets/pdffiles/Final_part1_2/EuP_Domestic Partlen2_V11.pdf> Acesso em: 13 set. 2012.

WANG, J.; FENG, X.; ANDERSON, C.W.N.; XING, Y.; SHANG, L. (2012) Remediation of mercury contaminated sites - A rewiew. Journal of Hazardous Materials, v. 221-222, p. 1-8 